\title{
Improving childbirth outcomes: an opportunity for infection prevention
}

\author{
Patricia Lynch
}

10.3396/ijic.V5i1.009.09

\begin{abstract}
Peri-natal infections
In many parts of the world, very high rates of complications and infections are part of the birth process. Infection prevention is integral to the problem and must be part of the solution. Low cost, effective infection prevention interventions are necessary immediately. ${ }^{1}$
\end{abstract}

Approximately 4 million neonates die every year in their first 28 days of life, $99 \%$ of them in low-resource settings. ${ }^{2}$ Neonatal infections alone are estimated to cause 1.6 million annual deaths or $40 \%$ of all neonatal deaths in developing countries. ${ }^{3}$ Delivering mothers are also at great risk. Approximately 500,000 women die of childbirth complications and millions more develop fistula and other

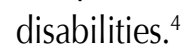

Childbirth complications including infections are primarily associated with poverty. They affect women and babies in all countries and are most frequent among those who lack access to adequate care. A Canadian researcher examined the effect of neighbourhood income and maternal education on birth outcomes and found a correlation between relative poverty and higher fatalities for babies. There was a significant disparity between death rates in the highest income $20 \%$ (quintile) of the population compared to those in the lowest $20 \% .{ }^{5}$ This relative disparity probably exists in all countries.
Healthcare-associated infections play a significant role in neonatal mortality among hospital-born babies in lowresource settings with rates 3-5 times greater than those reported by the NHSN in the US. ${ }^{6,7}$

\section{Potential solutions and role for infection prevention}

The best results have come from simple but comprehensive strategies that included improved community programs for prenatal care, hygienic delivery and neonatal management. At least three elements are essential to transform this problem into a global success story:

1. Public awareness and knowledge about pregnancy, childbirth and infant wellness must increase.

2. Community care must be available early in pregnancy to provide assessment, instructions, referral paths and safe delivery.

3. Hospital infections must be eliminated where possible. Mortality from hospital infections is very high and makes hospital care for women with problem pregnancies, preterm labor or sick newborns unpredictable, expensive and undesirable for families and physicians, even when institutional care is needed.

All three of these critical elements require participation, cooperation and innovation from organizations involved in maternal-child care all countries. Presently, these

\section{Corresponding author}

Patricia Lynch, RN, MBA, Chair, IFIC Safe Childbirth Special Interest Group, Email: plynch@aol.com 
organizations tend to not work together and none of them relate to hospital care. Countries that have significantly improved outcome for mothers and babies have had most or all of these organizations working together to increase public awareness about pregnancy, to make community assessment and care better, and to link in hospital complications prevention. There is an opportunity for infection prevention societies to make a significant contribution by initiating the communication and planning that would get cooperation going. Hospital infection prevention personnel are quite capable and well-placed to foster this cooperation.

\section{References}

1. Zaidi AK, Huskins WC, Thayer D, et al. Hospital-acquired neonatal infections in developing countries. Lancet 2005; 365: 1175-1188.

2. Zupan J, Aahman E. Perinatal mortality for the year 2000: estimates developed by WHO. Geneva: World Health Organization, 2005.

3. Lawn JE, Cousens S, Bhutta ZA, et al. Why are 4 million newborn babies dying each year? Lancet 2004; 364: 399401.

4. Ronsman C, Graham W. Maternal mortality: Who? When? Where? Why? Lancet 2006; 368: 1189-1200.

5. Luo ZC, Kierans WJ, Wilkins R, Liston RM, Mohamed J, Kramer MS. Disparities in birth outcomes by neighborhood income: temporal trends in rural and urban areas, British Columbia. Epidemiology 2004; 15: 679-686.

6. Rosenthal VD, Maki DG, Mehta A, et al. International Nosocomial Infection Control Consortium report, data summary for 2002-2007. Am J Infect Control 2008; 36: 627637.

7. Edwards JR, Peterson KD, Andrus ML, et al. National Healthcare Safety Network (NHSN) Report, data summary for 2006 through 2007, issued November 2008. Am J Infect Control 2008; 36: 609-626. 